\title{
A case of unilateral congenital triangular alopecia
}

\section{Przypadek jednostronnego wrodzonego łysienia trójkątnego}

\author{
Murat Ozturk', Isa An², Erhan Ayhan³, Sevda Onder ${ }^{4}$
}

'Department of Dermatology, Health Sciences University, Van Training and Research Hospital, Van, Turkey 2Department of Dermatology, Sanliurfa Training and Research Hospital, Sanliurfa, Turkey

3Department of Dermatology, Health Sciences University, Diyarbakir Gazi Yasargil Training and Research Hospital, Diyarbakir, Turkey ${ }^{4}$ Department of Dermatology, Medical Faculty, Ordu University, Ordu, Turkey

A 5-year-old male patient presented with hair loss on his scalp. It was discovered that he used topical glucocorticosteroids with the diagnosis of alopecia areata. There was no one in his family who had similar complaints. Dermatological examination revealed a patch of alopecia, approximately $5 \times 3 \mathrm{~cm}$ in size, with normal skin color, with vellus hair on it (fig. 1). Exclamation hair and yellow-white spots were not seen (fig. 2). With these findings, the patient was diagnosed with congenital triangular alopecia (CTA).

CTA, also called temporal triangular alopecia (TTA), is a type of persistent alopecia that is asymptomatic and non-cicatricial. It usually manifests as an alopecia without any cutaneous changes limited to the frontotemporal region of the scalp. Alopecia can be triangular, oval or lancet shaped. Fine vellus hair may be present $[1,2]$. The alopecic patch in our case was located in the frontotemporal region and was triangular shaped.

It is a disorder considered congenital, but it is also thought to be acquired due to the miniaturization of the hair follicles that make up the vellus hair. It is usually sporadic but rarely can be familial, and this is considered a paradominant feature [2]. CTA usually occurs at the age of 2-5, but it can also occur from birth or develop in adulthood. Although it is generally unilateral, it can be bilateral in $20 \%$ of cases. The actual incidence is unknown, because the lesions are benign and limited. In an analysis of 6200 patients, triangular alopecia was detected in 7 of the patients [3].

Li et al. reported 126 cases of CTA in the literature published in PubMed between 1905 and 2015 [4].

Down syndrome, phakomatosis pigmentovascularis, iris nevus syndrome, bone and tooth abnormalities, congenital heart diseases, mental retardation
Przedstawiamy przypadek 5-letniego chłopca z ogniskiem łysienia w obrębie skóry owłosionej głowy. W wywiadzie ustalono, że u pacjenta stosowano zewnętrznie glikokortykosteroidy z powodu rozpoznania łysienia plackowatego. U żadnego członka rodziny nie występowały podobne objawy. $\mathrm{W}$ badaniu dermatologicznym stwierdzono ognisko łysienia z włosami meszkowymi o wymiarach ok. $5 \times 3 \mathrm{~cm}$, zabarwienie skóry w obrębie ogniska było prawidłowe (ryc. 1). Nie zaobserwowano włosów wykrzyknikowych i żółto-białych kropek (ryc. 2). Na podstawie tego obrazu klinicznego u pacjenta rozpoznano wrodzone łysienie trójkątne (congenital triangular alopecia - CTA).

Wrodzone łysienie trójkątne, zwane również łysieniem skroniowym trójkątnym (temporal triangular alopecia - TTA), jest jedną z odmian trwałego łysienia, które przebiega bezobjawowo i jest niebliznowaciejące. Zazwyczaj CTA manifestuje się obecnością ogniska utraty włosów na skórze głowy, ograniczonego do obszaru czołowo-skroniowego, bez innych towarzyszących zmian skórnych. Ognisko łysienia może mieć kształt trójkątny, owalny lub lancetowaty. W obrębie zmiany mogą być widoczne cienkie włosy meszkowe [1, 2]. W opisywanym przypadku ognisko łysienia było umiejscowione w okolicy czołowo-skroniowej i miało kształt trójkątny.

Uważa się, że CTA ma podłoże wrodzone, ale może mieć również charakter nabyty i rozwijać się wskutek miniaturyzacji mieszków włosowych, z których następnie wyrastają cienkie włosy meszkowe. Zwykle pojawia się sporadycznie, choć rzadko może też występować rodzinnie - wtedy uznawane jest za cechę paradominującą [2]. Zazwyczaj rozwija się w wieku 2-5 lat, ale może również występować od urodzenia lub pojawić się w wieku dorosłym. Choć typowe jest występowanie jednostronne, w $20 \%$ przypadków CTA może być umiejscowione obustronnie. Rzeczywista częstość występowania jest 


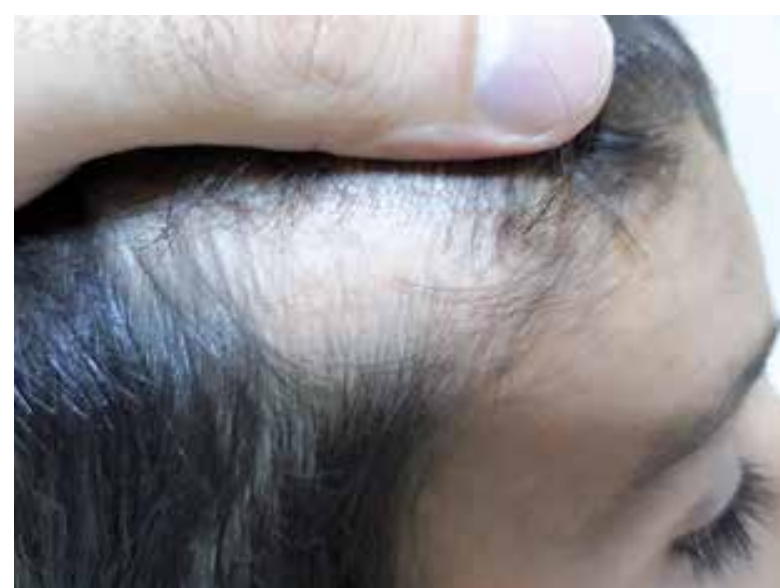

Figure I. Alopecia patch with vellus hair on it

Rycina I. Ognisko łysienia z widocznymi włosami mieszkowymi

and congenital aplasia cutis have been associated with CTA [2]. There was no sign of abnormality in our case.

Dermoscopy shows normal follicular openings and vellus hair in the alopecia patch. There are no yellow and black spots or dystrophic hairs. These features distinguish CTA from other non cicatricial -cicatricial alopecias such as aplasia cutis congenita, alopecia areata and trichotillomania. In CTA, hair follicles are miniaturized and vellus hairs fill the hair follicles as in androgenetic alopecia [5]. There is no specific treatment for CTA. Therefore, it is important to make the appropriate diagnosis to avoid unnecessary treatments and interventions. Topical minoxidil can be tried. Hair transplant and surgical excision of the lesion are the main treatment recommendations in patients with aesthetic concerns. While full excision may be considered for small lesions, others may require hair restoration surgery $[2,5]$.

In conclusion, CTA cases are scarce and it may mix with alopecia areata.

\section{CONFLICT OF INTEREST}

The authors declare no conflict of interest.

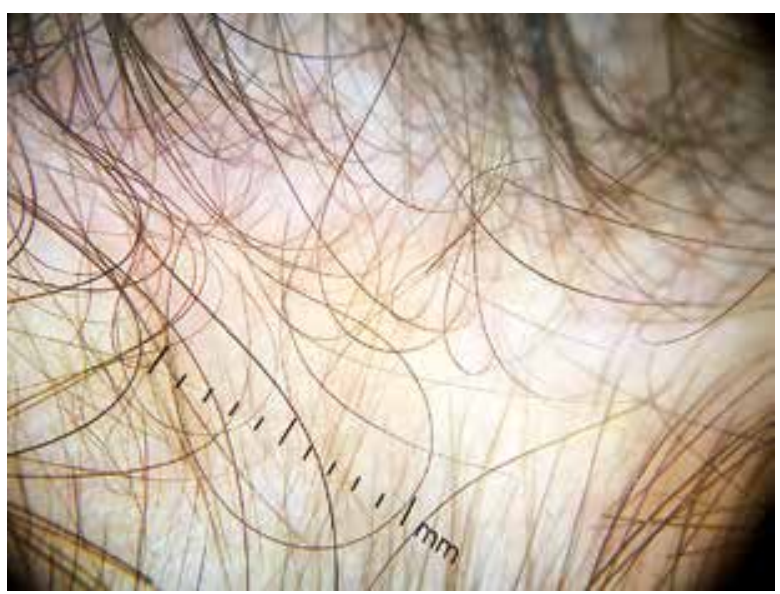

Figure 2. Dermoscopy shows thin vellus hairs and absence of exclamation hair and yellow-white spots

Rycina 2. Badanie dermoskopowe uwidacznia cienkie włosy mieszkowe, brak włosów wykrzyknikowych i żótto-białych kropek

nieznana, ponieważ zmiany mają charakter łagodny i ograniczony. W analizie dotyczącej 6200 osób łysienie trójkątne stwierdzono u 7 pacjentów [3].

Li i wsp. stwierdzili, że w publikacjach zawartych w bazie PubMed w latach 1905-2015 przedstawiono łącznie 126 przypadków CTA [4].

Wśród schorzeń związanych z CTA opisano zespół Downa, fakomatozę barwnikowo-naczyniową, zespół znamion barwnikowych tęczówki, wady kości i zębów, wrodzone wady serca, niepełnosprawność intelektualną oraz wrodzoną aplazję skóry [2]. W naszym przypadku nie występowały żadne inne nieprawidłowości.

W dermoskopii uwidoczniono prawidłowe ujścia mieszków włosowych i włosy meszkowe w obrębie ogniska łysienia. Nie stwierdzono żółtych i czarnych kropek włosów dystroficzych. Cechy te pozwalają różnicować CTA z innymi postaciami łysienia niebliznowaciejącego, takimi jak niedorozwój wrodzony skóry, łysienie plackowate i trichotillomania. W przebiegu CTA mieszki włosowe ulegają miniaturyzacji, ponadto w mieszkach włosowych obecne są włosy meszkowe, podobnie jak w przypadku łysienia androgenowego [5]. Nie istnieje żadne swoiste leczenie CTA, dlatego tak istotne jest prawidłowe rozpoznanie schorzenia, aby uniknąć niepotrzebnego wdrażania leczenia i innych interwencji. Można podjąć próbę miejscowej terapii minoksydylem. W przypadku pacjentów, dla których ważny jest aspekt estetyczny, zalecenia terapeutyczne obejmują przeszczep włosów i chirurgiczne wycięcie zmiany. $W$ przypadku małych ognisk można rozważyć całkowite wycięcie, natomiast większe zmiany wymagają przeszczepienia włosów $[2,5]$.

Podsumowując - liczba przypadków CTA jest niewiel$\mathrm{ka}$, a schorzenie wymaga starannego różnicowania z łysieniem plackowatym.

\section{KONFLIKT INTERESÓW}

Autorzy nie zgłaszają konfliktu interesów. 


\section{References}

\section{Piśmiennictwo}

1. Fernández-Crehuet P., Vaño-Galván S., Martorell-Calatayud A., Arias-Santiago S., Grimalt R., Camacho-Martínez F.M.: Clinical and trichoscopic characteristics of temporal triangular alopecia: a multicenter study. J Am Acad Dermatol 2016, 75, 634-637.

2. Patel D.R., Tandel J.J., Nair P.A.: Congenital triangular alopecia - a case report. Int J Trichol 2020, 12, 89-92.

3. Dey V.K., Bhadoria T.S., Saxena A., Jaisinghani A.K., Patil A.Y., Dubey N.: Congenital triangular alopecia: the $127^{\text {th }}$ case. Int J Trichol 2016, 8, 50-51.

4. Li V.C., Yesudian P.D.: Congenital triangular alopecia. Int J Trichology 2015, 7, 48-53.

5. Zhao Y.L., Zhang R.Z.: Congenital triangular alopecia: a brief report. Int J Trichol 2018, 10, 290-291.

Received: 23.06 .2020

Accepted: 25.07.2020

Otrzymano: $23.06 .2020 \mathrm{r}$

Zaakceptowano: $25.07 .2020 \mathrm{r}$.

How to cite this article

Ozturk M., An I., Ayhan E., Onder S.: A case of unilateral congenital triangular alopecia. Dermatol Rev/Przegl Dermatol 2020, 107, 393-395. DOI: https://doi.org/10.5114/dr.2020.99883. 